\title{
Reduced Pulmonary Function is Age-Dependent in the Rat Lung IN NORMOXIA
}

\author{
G. Petruccelli1 1 , V. Verratti ${ }^{1}$, J. Antosiewicz 2 , A. Cataldi ${ }^{3,4}$, A. Mazzatenta ${ }^{1}$, C. Di Giulio ${ }^{1}$ \\ ${ }^{1}$ Department of Neuroscience and Imaging, 'G. d'Annunzio' University of Chieti-Pescara, Italy; \\ ${ }^{2}$ Department of Respiratory Research, Medical Research Center, Polish Academy of Sciences, Warsaw, Poland; \\ ${ }^{3}$ Department of Medicine and Aging Sciences and ${ }^{4}$ Department of Human Anatomy, Faculty of Pharmacy, 'G. d'Annunzio' University \\ of Chieti-Pescara, Italy
}

\begin{abstract}
Background: Oxygen transport is optimized at the cellular level, since oxygen serves as the terminal electron acceptor in mitochondrial oxidative phosphorylation and several enzymatic processes require molecular oxygen as substrate. During development and aging, redundant cells and exhausted cells are eliminated, respectively, whereas others can adapt to the stressful environment and survive.

Objective: The study investigated the molecular mechanisms activated in the lung during normal aging, through the expression of hypoxia inducible factor (HIF), vascular endothelial growth factor (VEGF), p53, p66 Shc , putative cysteine protease (CPP32) and kinase $\mathrm{B}-\alpha$ phosphorylation ( $\mathrm{pIkB}-\alpha$ ).

Material and methods: Twelve male Wistar rats divided into two age-groups, each consisting of 6 animals, 3 and 24 months old, were used. The rats were anesthetized with Nembutal (40 $\mathrm{mg} / \mathrm{kg}$, ip) and the lungs were excised from each rat and processed for TUNEL and Western blotting analyses.

Results: The expressions of p53, p66 Shc and CPP32 were significantly increased in the old normoxic rat lung specimens, when compared with the young ones. In parallel, expressions of VEGF and $\mathrm{pIkB} \alpha$ were increased in old rather than young rats.

Conclusions: Aging leads to increased expressions of p53, p66 She and CPP32, suggesting that apoptosis is in progress. At the same time, the lung tries to counteract apoptosis through the production of VEGF and pIkB- $\alpha$ to adapt itself to a stressful situation. The aging lung creates a life-support system in order to counteract the apoptotic process.
\end{abstract}

Key words: lung, apoptosis, aging, p53

\section{INTRODUCTION}

The lung is the essential respiratory organ in all airbreathing animals and its principal function is to transport oxygen from the atmosphere into the bloodstream and to release carbon dioxide from the bloodstream into the atmosphere. Normally, the partial pressure of oxygen $\left(\mathrm{PO}_{2}\right)$ decreases from the lung to mitochondria with the changing distance of oxygen diffusion to tissues [1]. To counteract the low availability of oxygen, which is the most physiological stimulus for angiogenesis [2], cells reorganize themselves through the angiogenesis and subsequent remodeling while the oxygen transport is optimized, since oxygen serves as the terminal electron acceptor in mitochondrial oxidative phosphorylation and several enzymatic processes require molecular oxygen as substrate. Functionality of the lung is related to aging, which is a physiological condition characterized by a modification of structure and geometry of tissues which undergo a progressive lost in elasticity (i.e., in both blood vessels and pulmonary tissue) and by a general reduction of the homeostatic capacity along with a decrease in oxygen supply to tissues. During aging the diffusion distance between the lung and mitochondria elongates along with a progressive decrease in maximum consumption of oxygen $\left(\mathrm{VO}_{2 \max }\right)$. The regulation of pulmonary function and its adaptive capacity depends on specific feedback mechanisms initiated by chemoreceptors. The molecular mechanism of cell sensitivity to oxygen is still unknown [3]. During development and aging, redundant cells and exhausted cells are eliminated, respectively, whereas other cells can adapt to the stressful environment and survive. The factors that determine the fate of each cell are probably influenced by the main mechanism regulating gene expression [4]. Upon interaction with an external stimulus, such a mechanism involves a series of chemical steps that transduce signals into the nucleus and lead to induction or repression of transcription [5,6]. This can bring about apoptosis [7, 8] of exhausted cells during aging [9] or those injured by oxidative stress [10].

Since aging is a condition in which there already is a decrease of oxygen supply to tissue, the hypothesis of this work was that the lung could be able to create a life-support system, adapting to stressful situations caused by reduced oxygen supply to tissue. Among the molecules involved in such a mechanism, a role has been assigned to p53 $[11,12]$. The p53 tumor suppressor protein triggers cell cycle arrest and apoptosis in response to cellular stresses such as DNA damage, hypoxia and oncogene activation. In particular, this 
molecule seems to play a role in stabilizing hypoxia-inducible factor-1 $\alpha$ (HIF-1 $\alpha)[13,14]$. HIF-1 $\alpha$ DNAbinding protein is a heterodimer composed of two subunits: HIF-1 $\beta$, which can dimerize with different basic helix-loop-helix PAS proteins, and HIF-1 $\alpha$, which is the $\mathrm{O}_{2}$-regulated subunit that determines the biological activity of the molecule. Thus, the aim of this work has been to investigate the molecular mechanism activated during aging by the lung, through the expression of p53 and HIF-1 $\alpha$, but also of vascular endothelial growth factor (VEGF) which gives a signal produced by cells to stimulate the growth of new blood vessels, part of the response aimed at restoring oxygen supply to tissue when blood circulation is inadequate, $\mathrm{p} 66^{\mathrm{Shc}}$ which is a protein that translates oxidative damage into cell apoptosis and increases upon apoptotic stimulation in a p53-dependent way [15], caspase-3 (CPP32) which is a prototypical caspase that becomes activated during apoptosis [16], and kinaseB- $\alpha$ phosphorylation (pIkB- $\alpha$ ), an important molecule involved in cellular survival pathways by inhibiting apoptotic processes.

\section{Material And Methods}

\section{AnImaLs}

Two groups, each composed of 6 male Wistar rats, three-months (weight 200-250 g) and twenty-four (weight 350-400 g) months old, were used according to the guidelines of the Declaration of Helsinki for care and use of experimental animals. Only animals free of acute and chronic illness were employed. The rats were anesthetized with Nembutal $(40 \mathrm{mg} / \mathrm{kg}$, i.p.) and the lungs, excised from each rat, was processed for TUNEL and Western blotting analysis. In parallel we have also applied a hypoxic condition $\left(8 \% \mathrm{O}_{2}\right)$ for the same number of animals for the same days (data and results not shown in this article).

\section{TunEL STAINING}

Terminal deoxynucleotidyl transferase-mediated dUTP-biotin nick end-labeling (TUNEL) is a method of choice for a rapid identification and quantification of apoptotic cells. DNA strand breaks, yielded during apoptosis, can be identified by labeling free 3'-OH terminals with modified nucleotides in an enzymatic reaction. Paraffin-embedded tissue sections (dewaxed, rehydrated, and preincubated with proteinase $\mathrm{K} 20$ $\mu \mathrm{g} / \mathrm{ml}$ in $10 \mathrm{mmol} / \mathrm{l}$ Tris- $\mathrm{HCl}$ at $\mathrm{pH}$ 7.6) were exposed to the TUNEL mixture according to the manufacturer's instructions (Boehringer Mannheim, Germany). After two rinses in phosphate-buffered saline, the slides were mounted by using a propidium iodide-glycerol solution $(10 \mu \mathrm{g} / \mathrm{ml})$ and analyzed under a fluorescence microscope (Leica Microsystems, Wetzlar, Germany). Negative controls were prepared by omitting incubation in the presence of the enzymatic mixture (data not shown).

\section{WESTERN BLOTTING}

Total cell lysates or immunoprecipitated proteins was electrophoresed and transferred to nitrocellulose. Ni- trocellulose, blocked in 5\% nonfat milk, $10 \mathrm{mmol} / \mathrm{l}$ Tris at $\mathrm{pH} 7.5,100 \mathrm{mmol} / 1 \mathrm{NaCl}$, and $0.1 \%$ Tween 20 , was probed with HIF-1 $\alpha$, VEGF, p53, p66shc, CPP32, and pIkB- $\alpha$ antibodies (Santa Cruz Biotechnology, Santa Cruz, CA) and the incubated in the presence of specific IgG horse-radish peroxidase conjugate. Immunoreactive bands were detected by means of an ECL detection system (Amersham International, Little Chalfont, UK) and analyzed by densitometry.

\section{Image Processing}

Quantitative analysis of protein expression was performed by using a Sony video camera connected to a Leica Quantimet 500 plus software (Leica Cambridge Ltd., Cambridge, UK) determining the change in integrated optical intensity (IOI) using ISO transmission density Kodak CAT 152-3406 (Eastman Kodak Company, Rochester, NY) as standard.

\section{STATISTICAL Evaluation}

Results were expressed as means \pm SD of eight different experiments. The values obtained from 12-15 electron micrographs were averaged for any given lung. The mean values were calculated from the morphometric measurements of cell parameters. Statistical comparison between the young group and the corresponding age-matched control group, was performed using an unpaired $t$-test, with the values of $\mathrm{P}<0.01$ considered significant (GraphPad Prism Software, Version 5.0). The same analysis was performed for the old group.

\section{RESULTS}

TUNEL analysis revealed an increase in the number of apoptotic cells in 3 normoxic specimens of old lungs compared with the young ones. HIF-1 $\alpha$ levels were almost the same in both young and old rats (Fig. 1 and Fig. 2A). Since HIF-1 $\alpha$ can bind to the tumor suppressor factor p53 and promote p53-dependent apoptosis by inducing pro-apoptotic proteins, the p53 detected by Western blotting was increased in old compared with young rats (Fig. 1 and Fig. 2A). Oxidative stress is closely related to the aging processes [17]; therefore, expression of p66 Shc, the molecule involved in controlling the life-span in mammals, was evaluated. The p66 levels were significantly increased in old compared with young rats (Fig. 1 and Fig. 2B). As described for $\mathrm{p} 53$, the p66 6 Shc protein could also have a role in HIF-1 $\alpha$ stabilization [18-21].

Furthermore, in the old rats a substantially increased CPP32 expression was observed (Fig. 1 and Fig. 2C). VEGF, detected by Western blotting, can be induced in cells that are not receiving enough oxygen. When a cell is deficient in oxygen, it produces HIF which stimulates the release of VEGF among other functions (including modulation of erythropoiesis). The expression of VEGF was also increased in the old rats (Fig. 1 and Fig. 2C). At the same time there also was a significantly higher expression of $\mathrm{pIkB}-\alpha$ in the old rats (Fig. 1 and 2B). 


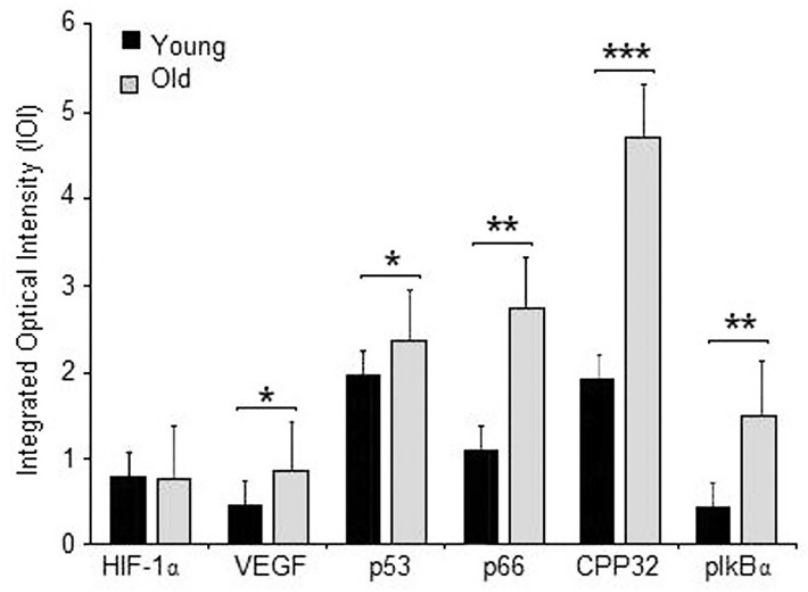

Fig. 1. Expressions of the studied proteins involved in the aging process in young and old rat lungs. Quantitative analysis determining the change in integrated optical intensity (IOI) was normalized against the mouse $\alpha$-sarcomeric actin. Results are means $\pm S D(n=3)$ for all groups. Normoxic young vs. normoxic old - $* \mathrm{P}<0.01$ for $\mathrm{VEGF}$ and $\mathrm{p} 53$; $* * \mathrm{P}<0.001$ for $\mathrm{p} 66^{\mathrm{Shc}}$ and $\mathrm{pIkB}-\alpha$; and $* * * \mathrm{P}<0.0001$ for СРP32.

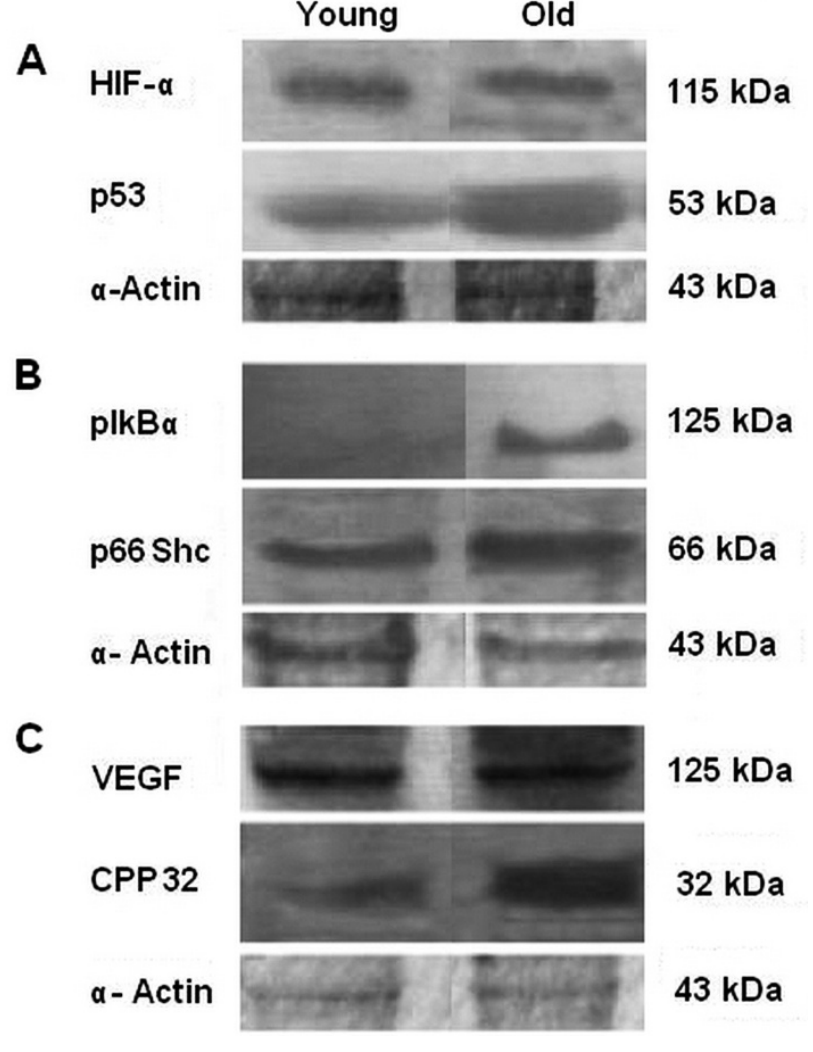

Fig. 2. Western blots demonstrating the studied proteins involved in the aging process in young and old rat lungs.

\section{Discussion}

Apoptosis is a tightly regulated endogenous cell death program requiring executing proteases. Among the events that determine apoptosis, development, aging, and reduction in oxygen tension are included. During development, apoptosis consists of three types of cell death: phylogenetic, histogenetic, and morphogenetic cell death [8]. During adult and aged life, apoptosis serves to maintain homeostasis by counterbalancing mitosis and deleting vestigial cells which are potentially immunoreactive, malignant, or virus infected. In addition, with age, a progressive decline in cell function can be observed, related either to a genetic program or to accumulation of stochastic errors in somatic cells [22]. However, lipid peroxidation, protein modification, enzyme inactivation, DNA strand breaks, and base modifications are induced, and oxidative damage results $[23,24]$.

Obviously, the degree to which a pathway is activated depends on the nature and duration of stress as well as on the cell type. Thus, here we tried to match the responses of a rat lung during aging in terms of expression and activation of HIF-1 $\alpha$, p53, p66 Shc, CPP32, VEGF, and pIkB- $\alpha$. Aging and reduced oxygen supply to tissue are two stressful events involved in the induction of HIF-1 $\alpha$ expression, activation, and apoptosis [25]. HIF-1 $\alpha$ is a key cellular modulator controlled by many different pathways [19]. In the old lungs, HIF-1 $\alpha$ expression was not modified compared with young ones. Aging led to increased expression of p53, p66 Shc and CPP32 in lungs. These data suggest that apoptosis was in progress. At the same time, the lung tries to counteract apoptosis through the production of VEGF and pIkB- $\alpha$ to adapt itself to a stressful situation and subsequent low availability of oxygen for tissues. The lung may thus attempt to create a lifesupport system to counteract the apoptotic process and free radical production in the course of the life span.

Acknowledgments: The first author wish to thank Profs. Camillo Di Giulio, Amelia Cataldi, and Dr. Vittore Verratti for their moral support and unconditional help during the three years of a Ph.D. course.

Conflicts of interest: The authors declare no conflicts of interest in relation to this article.

\section{REFERENCES}

1. Law R, Bukwirwa H. The Physiology of Oxygen Delivery. Update in Anaesthesia. 1999; 10: 3.

2. Shweiki D, Itin A, Soffer D, Keshet E. Vascular endothelial growth factor induced by hypoxia may mediate hypoxia-initiated angiogenesis. Nature 1992; 359: 843-5.

3. Kummer W, Yamamoto Y. Cellular distribution of oxygen sensor candidates-oxidases, cytochromes, $\mathrm{K}^{+}$-channels in the carotid body. Microsc Res Tech 2002; 59: 23442.

4. Bianchi G, Di Giulio C, Rapino C, Rapino M, Antonucci A, Cataldi A. p53 and p66 proteins compete for hypoxiainducible factor- $1 \alpha$ stabilization in young and old rat hearts exposed to intermittent hypoxia. Gerontology 2006; 52: 17-23.

5. Ostadal B, Ostadalova I, Dhalla NS. Development of cardiac sensitivity to oxygen deficiency: comparative and ontogenetic aspects. Physiol Rev 1999; 79: 635-59.

6. Bunn HF, Poyton RO. Oxygen sensing and molecular adaptation to hypoxia. Physiol Rev 1996; 76: 839-85.

7. van den Hoff MJ, van den Eijnde SM, Viragh S, Moorman AF. Programmed cell death in the developing heart. Cardiovasc Res 2000; 45: 603-20. 
8. Centurione L, Di Giulio C, Cacchio M, Rapino M, Bosco D, Grifone G, Sabatini N, Bianchi G, Castorina S, Antonucci A, Cataldi A. Correlations between protein kinase $\mathrm{C} \zeta$ signaling and morphological modifications during rat heart development and aging. Mech Ageing Dev 2003; 124: 957-66.

9. Higami Y, Shimokawa I. Apoptosis in the aging process. Cell Tissue Res 2000; 301: 125-32.

10. Cesselli D, Jakoniuk I, Barlucchi L, Beltrami AP, Hintze TH, Nadal-Ginard B, Kajstura J, Leri A, Anversa P. Oxidative stress-mediated cardiac cell death is a major determinant of ventricular dysfunction and failure in dog dilated cardiomyopathy. Circ Res 2001; 89: 279-86.

11. Shen Y, White E. p53-dependent apoptosis pathways. Adv Cancer Res 2001; 82: 55-84.

12. Pan Y, Oprysko PR, Asham AM, Koch CJ, Simon MC. p53 cannot be induced by hypoxia alone but responds to the hypoxic microenvironment. Oncogene 2004; 23: 4975-83.

13. Suzuki H, Tomida A, Tsuruo T. Dephosphorylated hypoxia-inducible factor 1 -alpha as a mediator of p53-dependent apoptosis during hypoxia. Oncogene 2001; 20: 5779-88.

14. Semenza GL. HIF-1 and mechanisms of hypoxia sensing. Curr Opin Cell Biol 2001; 13: 167-71.

15. Trinei M, Berniakovich I, Beltrami E, Migliaccio E, Fassina A, Pelicci P, Giorgio M. p66 $6^{\text {Shc }}$ signals to age. Aging 2009; 1: 503-10.

16. Woo M, Hakem R, Soengas MS, Duncan GS, Shahinian A, Kägi D, Hakem A, McCurrach M, Khoo W, Kaufman SA, Senaldi G, Howard T, Lowe SW, Mak TW. Essential contribution of caspase 3/CPP32 to apoptosis and its associated nuclear changes. Genes Dev 1998; 12: 806-19.

17. Moskovitz J, Berlett BS, Poston JM, Stadtman ER. The yeast peptide-methionine sulfoxide reductase functions as an antioxidant in vivo. Proc Natl Acad Sci USA 1997; 94: 9585-9.
18. Migliaccio E, Giorgio M, Mele S, Pelicci G, Reboldi P, Pandolfi PP, Lanfrancone L, Pelicci PG. The p66Shc adaptor protein controls oxidative stress response and life span in mammals. Nature 1999; 402: 309-13.

19. Abe J, Berk BC. Hypoxia and HIF-1 $\alpha$ stability: another stress-sensing mechanism for Shc. Circ Res 2002; 91: 4-6.

20. Piret JP, Mottet D, Raes M, Michiels C. Is HIF-1 $\alpha$ a proor an anti-apoptotic protein? Biochem Pharmacol 2002; 64: 889-92.

21. Jung F, Haendeler J, Hoffmann J, Reissner A, Dernbach E, Zeiher AM, Dimmeler S. Hypoxic induction of the hypoxia-inducible factor is mediated via the adaptor protein Shc in endothelial cells. Circ Res 2002; 91: 38-45.

22. Camougrand N, Rigoulet M. Aging and oxidative stress: studies of some genes involved both in aging and in response to oxidative stress. Respir Physiol 2001; 128: 393401.

23. Finkel T, Holbrook NJ. Oxidants, oxidative stress and the biology of ageing. Nature 2000; 408: 239-47.

24. Michiels C, Minet E, Mottet D, Raes M. Regulation of gene expression by oxygen: NF-KB and HIF-1, two extremes. Free Radic Biol Med 2002; 33:1231-42.

25. An WG, Kanekal M, Simon MC, Maltepe E, Blagosklonny MV, Neckers LM. Stabilization of wild-type p53 by hypoxia-inducible factor 1-alpha. Nature 1998; 392: 405-8.

Address for correspondence:

C. Di Giulio

Department of Neuroscience and Imaging

"G. d'Annunzio" University

Campus Madonna delle Piane

Via dei Vestini

31-66100 Chieti

Italy

Phone: +3908713554044 